\title{
A Comparison Between Cut-Back and Standard Reference Fiber Techniques in Calibrating the Attenuation Scale of Optical Time Domain Reflectometers
}

\author{
Hatem Hussein* and Osama Terra \\ Primary Length Standard \& Laser Technology Laboratory, \\ National Institute of Standards (NIS), Tersa St. Haram, code:12211, \\ P.O.Box: 136 Giza, Egypt. \\ *Corresponding author:(ه hatem_hussein@hotmail.com).
}

In this paper, a comparison between the calibration of the attenuation scale of an Optical Time Domain Reflectometer (OTDR) using two different techniques is discussed and implemented. The first technique is the external modulation method (EM). A setup is proposed to calibrate an OTDR over a dynamic range of around $15 \mathrm{~dB}$ based on the EM method. Afterwards, the OTDR is calibrated using two standard reference fibers (SRFs). Both SRFs are calibrated using cut-back technique; one of them is calibrated at our home institute (the National Institute of Standards - NIS) while the other at the National Physical Laboratory (NPL) of the United Kingdom to confirm our results. In addition, the parameters contributing to the calibration uncertainty are thoroughly investigated. The measurement results are compared to that of the NPL through a previously calibrated fiber artifact. The OTDR calibration uncertainty of the EM method is found to be around $U\left(\Delta S_{A}\right)= \pm 0.1 \mathrm{~dB} / \mathrm{dB}$, while the calibration uncertainty of the $S R F$ method is found be around $U\left(\Delta S_{A}\right)$ $= \pm 0.04 \mathrm{~dB} / \mathrm{dB}$ for both $1310 \mathrm{~nm}$ and $1550 \mathrm{~nm}$ OTDR wavelengths.

\section{Introduction}

Optical fiber links can connect distances up to $250 \mathrm{~km}$ in a single step without repeaters. This puts stringent conditions on the loss introduced by such links and requires an accurate calculation of the attenuation budget. 
Optical time domain reflectometers (OTDRs) are widely used for the diagnosis of optical fibers in the production process and during installation of fiber networks. They are used to detect fault locations and measure attenuation along optical fiber links [1]. However, OTDR requires regular calibration to assure the required accuracy in attenuation and distance measurements. In a previous publication, distance scale calibration of OTDR is reported [2]. In this paper, the attenuation scale calibration of OTDR will be investigated.

Although, there are two methods recommended for the calibration of OTDR attenuation scale in EN 61746 [3], only the standard reference fiber method (SRF) has been investigated in scientific publications [4]; even though, the External Modulation method (EM) offers several advantages over the SRF method. It can be fully automated, easily operated and it offers traceability to the SI unit of power, the watt, through a calibrated variable digital attenuator.

In this work, a setup based on the EM method is proposed to calibrate accurately the attenuation scale of an OTDR. The parameters contributing to the calibration uncertainty are investigated. Two standard reference fibers (SRFs) are used to calibrate the same OTDR and the uncertainty is reported. Both SRFs are calibrated using the cut-back technique [3, 7]. One of the SRFs is calibrated at the national metrology institute of the United Kingdom (the NPL). The other is calibrated at our home institute using a wide-range externalcavity tunable didoe laser source $(1500-1630 \mathrm{~nm})$ to evaluate the spectral attenuation coefficient instead of the Tungsten-Halogen lamp and the monochromator implemented in [7]. Finally, a comparison between both OTDR calibration techniques is made.

\section{OTDR attenuation scale calibration using EM method}

The main goal of calibrating the attenuation scale of an OTDR is to find the attenuation scale deviation $\left(\Delta S_{A}\right)$ according to the following equation:

$$
\Delta S_{A}=\frac{A_{\text {otdr }}-A_{\mathrm{rgf}}}{A_{\mathrm{raf} f}}
$$

where, $A_{\text {otdr }}$ : the attenuation measured by the OTDR, $A_{\text {ref }}$ : the attenuation set by a digital variable attenuator (DVA reference) at each position which corresponds to a different power region of the OTDR scale.

The EM method can be described briefly as follows: EM method uses a digital delay generator (DDG) and a variable attenuator (VA) to simulate an OTDR trace by positioning a reflection at different locations and attenuations along the OTDR trace. At each position along the trace, a calibrated DVA is used to find the attenuation scale deviation. 


\subsection{EM calibration system}

Figure (1) shows the system used to calibrate the attenuation scale of an OTDR using the EM method. The system consists of a DFB laser (EM4, wavelength: $1556 \mathrm{~nm}$, linewidth: $1 \mathrm{MHz}$ ), an Acousto-Optic Modulator (NEOS Technologies, Frequency: $35 \mathrm{MHz}$ ), OTDR (Yokogawa, AQ1200), digital delay generator (SRS, DG645), a variable attenuator (Thorlabs-VOA-50), Digital attenuator: (Joinwit Optoelectronics), a photodetector (Agere-R2860D$10 \mathrm{GHz})$ and a beam splitter.

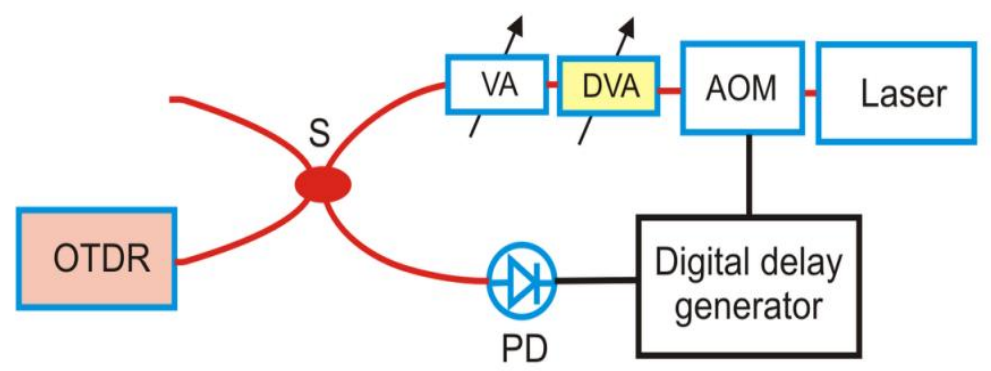

Fig. (1): OTDR calibration employing EM method; VA: optical variable attenuator, DVA: digital variable attenuator, AOM: Acousto-optic modulator, S: beam splitter, PD: photodetector.

The OTDR sends a modulated light pulses through a beam splitter to the photodetector, which converts the optical signal into an electrical one. The DDG delays the pulsed electrical signal by well-known and calibrated time delays. The AOM converts these electrical pulses back to laser pulses, which are sent back to the OTDR through a variable optical attenuator (VOA) and a DVA. The VOA is used to set the returned pulse at different power regions of the OTDR scale. The digital attenuator is used to provide reference attenuation at a well calibrated value. Afterwards, the average value and the standard deviation for $\Delta S_{A}$ are calculated for all the measured positions along the OTDR trace.

\subsection{Digital Variable Attenuator Calibration}

In order to guarantee that the results obtained from the previous setup provides a traceable calibration to the SI unit of power, the Watt, the DVA should be calibrated just prior to starting the OTDR attenuation scale calibration process. An integrating sphere-based power meter (Newport, 918D-IS-IG) is used to perform this calibration. The calibration system is shown in Fig. (2). 


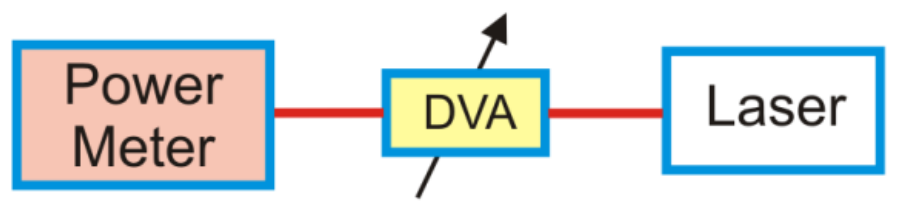

Fig. (2): Calibration of a digital variable attenuator (DVA).

After the DVA is switched on to warm-up for around 15 minutes, it is calibrated just prior to the experiment. Since it will be used only to introduce a standard attenuation of only $2 \mathrm{~dB}$, it is calibrated only at this range (from $0 \mathrm{~dB}$ $2 \mathrm{~dB})$.

\subsection{Results}

The result of calibration of the DVA is shown in Table 1 . The aim of the calibration is to find the offset and statistical uncertainty (standard deviation) from the reference value $(2 \mathrm{~dB})$ at $1550 \mathrm{~nm}$ and $1310 \mathrm{~nm}$ :

Table (1): DVA calibration results.

\begin{tabular}{|l|l|l|}
\hline Wavelength & Offset & Statistical uncertainty \\
\hline $1550 \mathrm{~nm}$ & $0.035 \mathrm{~dB}$ & $0.002 \mathrm{~dB}$ \\
\hline $1310 \mathrm{~nm}$ & $0.123 \mathrm{~dB}$ & $0.003 \mathrm{~dB}$ \\
\hline
\end{tabular}

Immediately after DVA calibration, the OTDR calibration procedure is started. The OTDR and the DDG pulse widths are adjusted to $10 \mu$ s to have flat-top pulse which facilitates the attenuation measurements. The VA and DGG are used to introduce attenuation steps of $4 \mathrm{~dB}$, and delay steps of $100 \mu \mathrm{s}$, respectively. The OTDR measures the $4 \mathrm{~dB}$ attenuation as if it is only $2 \mathrm{~dB}$ since it measures the two-way attenuation. Accordingly, these attenuation and delay steps produce 14 calibration positions for each of the $1550 \mathrm{~nm}$ and 1310 $\mathrm{nm}$ wavelengths as shown in Fig. $(3,4)$. These positions should lie in the region recommended by the standard BS/EN 61746 [3]. 


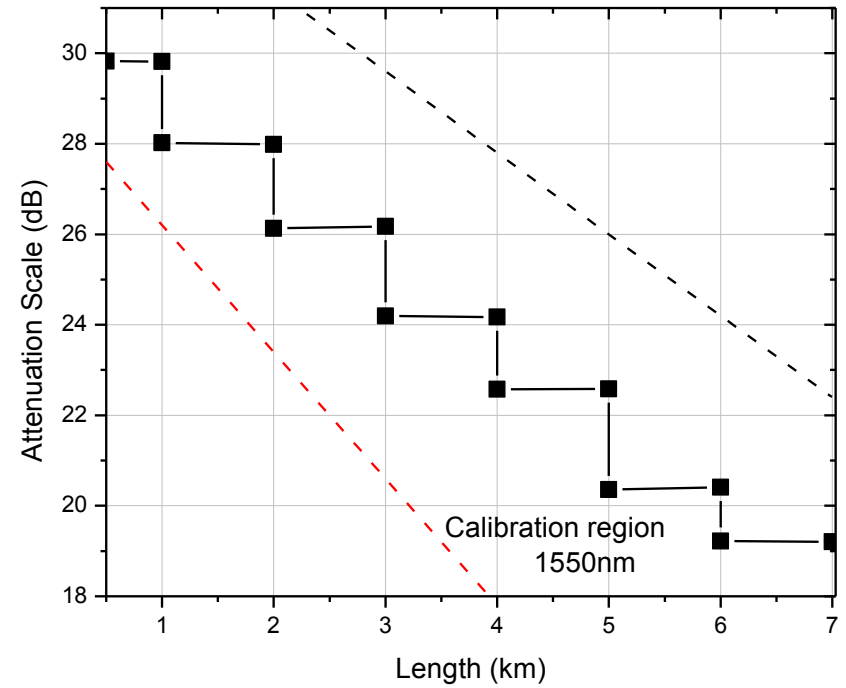

Fig. (3): Calibration positions (squares) for $1550 \mathrm{~nm}$ and the calibration region (between the dashed lines).

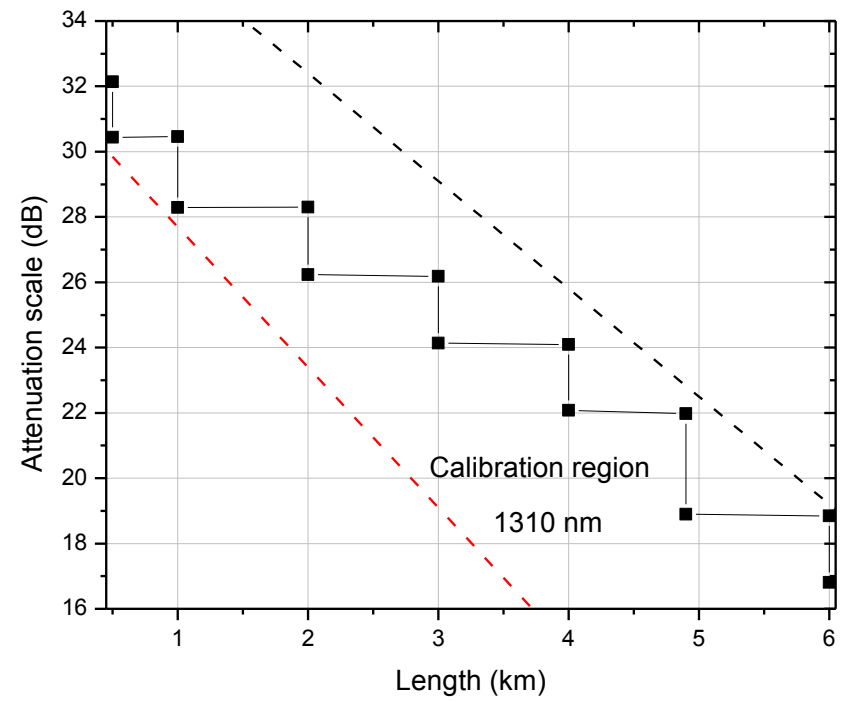

Fig. (4): Calibration positions (squares) for $1310 \mathrm{~nm}$ and the calibration region (between the dashed lines).

The loss scale deviation for $1550 \mathrm{~nm}$ is found to be $-0.014 \mathrm{~dB} / \mathrm{dB}$; with a standard deviation of $0.049 \mathrm{~dB} / \mathrm{dB}$. For $1310 \mathrm{~nm}$, it is found to be -0.023 $\mathrm{dB} / \mathrm{dB}$; with a standard deviation of $0.048 \mathrm{~dB} / \mathrm{dB}$. 


\subsection{Uncertainty Analysis}

In order to report the calibration result, uncertainties in the attenuation scale deviation $\left(\Delta S_{A}\right)$ should be estimated. The guide to the expression of the uncertainty in measurement (GUM) is used to calculate the uncertainties [8].

From Equation (1), the attenuation scale deviation can also be written as:

$$
\Delta S_{A}=\frac{A_{\text {otdr }}}{A_{\text {raf }}}-1
$$

The uncertainty in $\Delta S_{A}$ can be obtained by partially differentiating equation (2) and adding the terms in quadrature:

$$
u\left(\Delta S_{A}\right)=\sqrt{\left(\frac{\delta A_{\text {otdr }}}{A_{\text {ref }}}\right)^{2}+\left(\frac{A_{\text {otdr }} \delta A_{y e f}}{\left(A_{\mathrm{ref}}\right)^{2}}\right)^{2}}
$$

Multiplying equation (3) by $\left(\frac{A_{\text {rrff }}}{A_{\text {otdr }}} \approx 1\right.$ ), the equation becomes:

$$
u\left(\Delta S_{A}\right)=\sqrt{\left(\frac{\delta A_{\text {otdr }}}{A_{\text {otdr }}}\right)^{2}+\left(\frac{\delta A_{\text {ref }}}{A_{\text {ref }}}\right)^{2}}
$$

Where, $\left(\delta A_{\text {otdr }} / A_{\text {otdr }}\right)$ is the relative uncertainty of the OTDR attenuation scale. It includes the uncertainties due to the OTDR readout and the statistical contribution (standard deviation); $\left(\delta A_{y e f} / A_{y e f}\right)$ is the relative uncertainty of the reference attenuation of the DVA. Since, the STD is similar for $1550 \mathrm{~nm}$ and $1310 \mathrm{~nm}$, therefore, it is sufficient to calculate the uncertainty for one of them to be representing both. Table (2) summarizes the sources of uncertainty stated in equation (4) and its contribution to the attenuation scale deviation $\left(\Delta S_{A}\right)$.

Table (2): Uncertainty budget for $\left(\Delta S_{A}\right)$ at $1550 \mathrm{~nm}$ and $1310 \mathrm{~nm}$-External modulation method.

\begin{tabular}{|c|c|c|c|c|c|c|}
\hline $\begin{array}{c}\text { Source of } \\
\text { uncertainty }\end{array}$ & $\begin{array}{c}\text { Value } \\
( \pm)\end{array}$ & $\begin{array}{c}\text { Probability } \\
\text { distribution }\end{array}$ & Divisor & $\begin{array}{c}\text { Uncertainty } \\
( \pm)\end{array}$ & $\begin{array}{c}\text { Sensitivity } \\
\text { Coefficient }\end{array}$ & $\begin{array}{c}\text { Standard } \\
\text { uncertainty }\end{array}$ \\
\hline DVA & $0.002 \mathrm{~dB}$ & Normal & 1 & $0.002 \mathrm{~dB}$ & 1 & $\pm 0.002 \mathrm{~dB} / \mathrm{dB}$ \\
\hline $\begin{array}{c}\text { Statistical } \\
\text { contribution }\end{array}$ & $0.049 \mathrm{~dB} / \mathrm{dB}$ & Normal & 1 & $0.049 \mathrm{~dB} / \mathrm{dB}$ & 1 & $\pm 0.049 \mathrm{~dB} / \mathrm{dB}$ \\
\hline \multicolumn{2}{|l}{ Combined uncertainty } & & $\pm 0.049 \mathrm{~dB} / \mathrm{dB}$ \\
\hline \multicolumn{2}{|l}{ Expanded uncertainty $(\mathrm{k} \approx 2)$} & $\pm 0.098 \mathrm{~dB} / \mathrm{dB}$ \\
\hline
\end{tabular}


The combined uncertainty in $\Delta S_{A}$ is obtained by summing in quadrature the uncertainty contributions in Table (2) as follows:

$$
u_{c}\left(\Delta S_{A}\right)=\sqrt{(0.002)^{2}+(0.049)^{2}}= \pm 0.049 \mathrm{~dB} / \mathrm{dB}
$$

The expanded uncertainty in $\Delta S_{A}$ of $\left(u_{95}\left(\Delta S_{A}\right)= \pm 0.098 \mathrm{~dB} / \mathrm{dB}\right)$ is obtained by assuming infinite degrees of freedom (DOF) and hence the coverage factor is assumed to be $\mathrm{k} \approx 2$. The calibration uncertainty is dominated by the statistical contribution, which is caused mainly by the OTDR measurement uncertainty. However, the calibration system is able to calibrate OTDRs with measurement uncertainty as low as $\pm 0.004 \mathrm{~dB} / \mathrm{dB}$.

The final result of calibration of loss scale deviation is shown in Table 3 .

Table (3): OTDR attenuation calibration results.

\begin{tabular}{|l|l|l|}
\hline Wavelength & Loss scale deviation & Expanded uncertainty \\
\hline $1550 \mathrm{~nm}$ & $-0.014 \mathrm{~dB} / \mathrm{dB}$ & $\pm 0.098 \mathrm{~dB} / \mathrm{dB}$ \\
\hline $1310 \mathrm{~nm}$ & $-0.023 \mathrm{~dB} / \mathrm{dB}$ & $\pm 0.098 \mathrm{~dB} / \mathrm{dB}$ \\
\hline
\end{tabular}

\section{Standard Reference Fiber (SRF) Method}

\subsection{Method Description}

In order to implement this method, a calibrated fiber standard is connected to the OTDR through a variable attenuator, polarization controller and a set of lead-in fibers. The attenuator and the lead-in fibers help to place the fiber standard at different positions $\left(A_{\text {otdr }, i}\right)$ along the OTDR backscatter trace. A polarization controller is used to reduce polarization dependent loss (PDL) caused by the OTDR. The attenuation scale deviation $\left(\Delta \boldsymbol{S}_{A}\right)$ will be determined for the operating wavelengths of the OTDR at $1310 \mathrm{~nm}$ and $1550 \mathrm{~nm}$. The system is shown in Fig. (5).

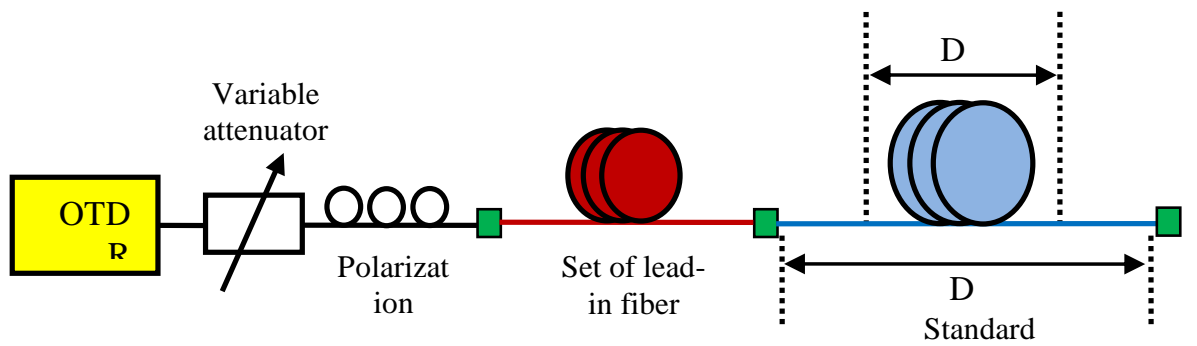

Fig. (5): OTDR calibration using standard reference fiber method (SRF). 
We have used two fiber standards that are calibrated using the cut-back technique [8] both at our institute (SRF_NIS) (see section 3.2.) and at the National metrology institute of UK (NPL) (SRF_NPL). The calibration of the OTDR attenuation scale deviation $\left(\Delta S_{A}\right)$ using the NPL artefact gives $\Delta S_{A}$ values of $-0.033 \mathrm{~dB} / \mathrm{dB}$ and $-0.030 \mathrm{~dB} / \mathrm{dB}$ for the $1550 \mathrm{~nm}$ and $1310 \mathrm{~nm}$ respectively with a statistical uncertainty of $0.01 \mathrm{~dB} / \mathrm{dB}$; while with the calibration with NIS artefact gives $\Delta S_{A}$ values of $-0.031 \mathrm{~dB} / \mathrm{dB}$ and -0.056 $\mathrm{dB} / \mathrm{dB}$ for the $1550 \mathrm{~nm}$ and $1310 \mathrm{~nm}$ respectively, with a statistical uncertainty of $0.008 \mathrm{~dB} / \mathrm{dB}$.

The wavelengths of the OTDR lasers are measured using an optical spectrum analyzer with an accuracy better than $\pm 0.1 \mathrm{~nm}$ and were found to be $(1547.7 \mathrm{~nm}$ and $1312.2 \mathrm{~nm})$. The results from both standard fibers are comparable.

\subsection{Cut-back technique}

The cut-back technique is a well-known destructive method to measure the attenuation of optical fibers $[3,7]$. It allows the attenuation measurement of a certain fiber without the influence of insertion loss. Unlike the previous work, an external-cavity tunable diode laser is implemented in this paper to measure the spectral attenuation, instead of the combination of a Tungsten-Halogen lamp and a monochromator. This allows sufficient optical power at the power meter without the need for a lock-in detection since the laser power of $(>2 \mathrm{dBm})$ is far exceeding the sources of noise from the power meter. The cut-back system includes an integrating sphere-based power meter (Newport, 918D-IS-IG), a tunable laser (Santec TSL-510) with a tuning range from 1500-1630 nm, and another DFB laser at $1310 \mathrm{~nm}$, as shown in Fig. (6). The power meter should be linear over the power measurement range.

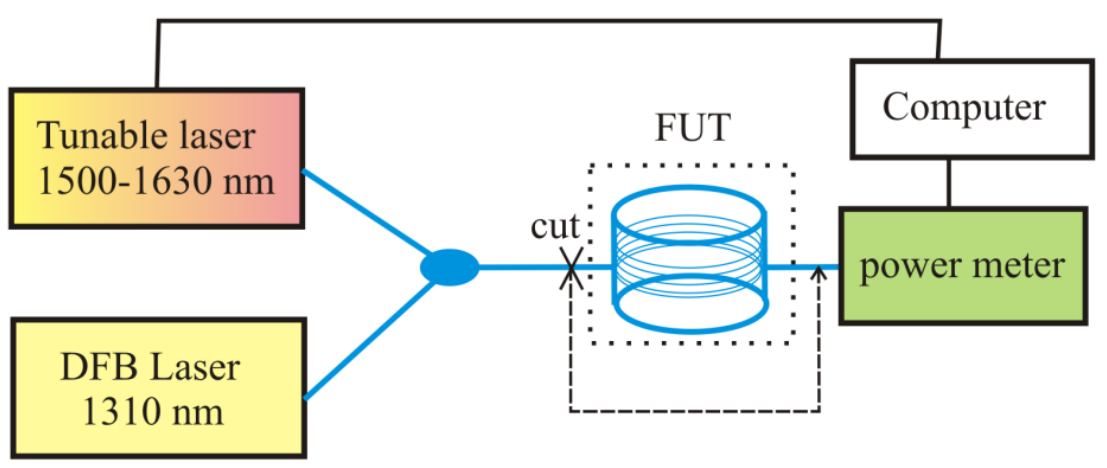

Fig. (6): Automated cut-back technique for attenuation measurement; FUT: fiber under test. 
The cut-back system is automated using a computer control to tune the wavelength of the tunable laser from 1500 to $1630 \mathrm{~nm}$ by steps of $5 \mathrm{~nm}$, while triggering the power meter to make a series of 120 measurements over 2 minutes at each wavelength. The Tunable laser is then switched off and the DFB laser is switched on to make another 120 measurements at $1310 \mathrm{~nm}$. Data from the power meter is transferred to the computer and both the mean and the standard deviation are calculated. The measurement is performed before and after removing the fiber under test (FUT). The FUT is removed by cutting and cleaving the fiber at (cut) position and then attaching it to the bare fiber adapter of the power meter. The attenuation is calculated by subtracting the mean power after from the mean power before removing the FUT. In order to calculate the attenuation coefficient, the fiber length before cutting is measured with a calibrated OTDR to be $10.152 \mathrm{~km}$ and the removed parts are measured with a ruler to be around $3 \mathrm{~m}$. The resulting spectral attenuation coefficient from $1500 \mathrm{~nm}$ to $1630 \mathrm{~nm}$ is shown in Fig. (7).

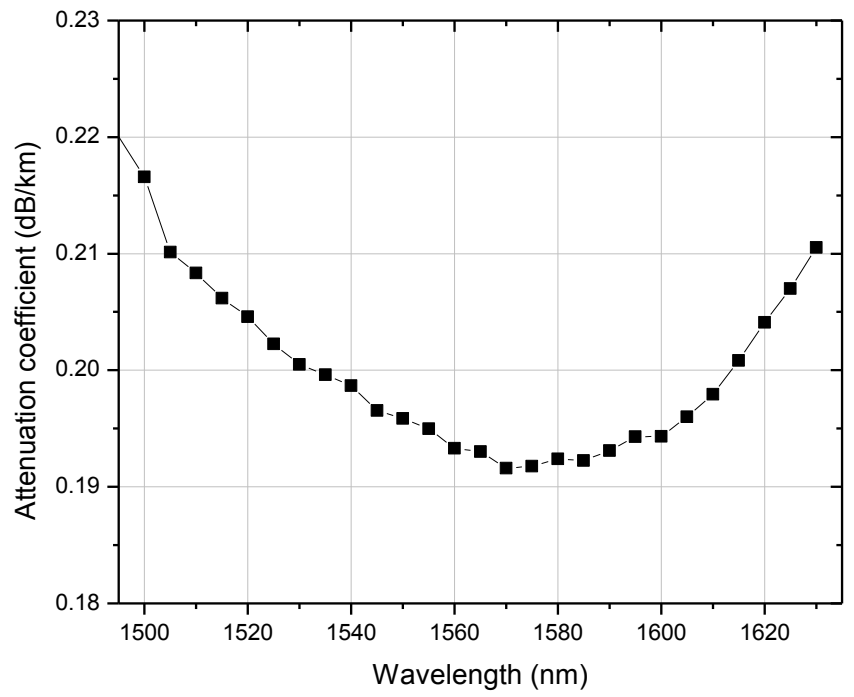

Fig. (7): Spectral attenuation coefficient.

The attenuation coefficient is measured for 1310nm using another DFB laser to be $0.346 \mathrm{~dB} / \mathrm{km}$. As shown from Fig. (7), the attenuation coefficient for $1550 \mathrm{~nm}$ is $0.196 \mathrm{~dB} / \mathrm{km}$ and the standard deviation of the measurement is $0.009 \mathrm{~dB}$. The uncertainty of the cut-back technique is evaluated at $1550 \mathrm{~nm}$ and $1310 \mathrm{~nm}$ according to Table 4 . 
Table (4): Uncertainty budget for the cut-back technique.

\begin{tabular}{|c|c|c|c|c|c|c|}
\hline $\begin{array}{c}\text { Source of } \\
\text { uncertainty }\end{array}$ & $\begin{array}{l}\text { Value } \\
( \pm)\end{array}$ & $\begin{array}{l}\text { Probability } \\
\text { Distribution }\end{array}$ & Divisor & $\begin{array}{c}\text { Uncertainty } \\
( \pm)\end{array}$ & $\begin{array}{l}\text { Sensitivity } \\
\text { Coefficient }\end{array}$ & $\begin{array}{c}\text { Standard } \\
\text { uncertainty }\end{array}$ \\
\hline $\begin{array}{l}\text { Power meter } \\
\text { nonlinearity }\end{array}$ & $0.010 \mathrm{~dB}$ & Normal & 1 & $0.010 \mathrm{~dB}$ & 1 & $\pm 0.010 \mathrm{~dB}$ \\
\hline $\begin{array}{l}\text { Statistical } \\
\text { contribution }\end{array}$ & $0.019 \mathrm{~dB}$ & Normal & 1 & $0.019 \mathrm{~dB}$ & 1 & $\pm 0.019 \mathrm{~dB}$ \\
\hline \multicolumn{6}{|c|}{ Combined uncertainty } & $\pm 0.021 \mathrm{~dB}$ \\
\hline \multicolumn{6}{|c|}{ Expanded uncertainty $(\mathrm{k} \approx 2)$ (assuming infinite degrees of freedom) } & $\pm 0.042 \mathrm{~dB}$ \\
\hline
\end{tabular}

\subsection{OTDR calibration uncertainty using SRF method}

According to equation 4, the OTDR attenuation scale calibration uncertainty originates from two sources: the OTDR measurement statistical uncertainty and the uncertainty in the attenuation of the SRF. The uncertainty budget for the calibration of the attenuation scale of OTDR using NPL and NIS artifacts are shown in Table 5 and 6 , respectively. Where, the combined uncertainty in the total attenuation for the NPL standard fiber is reported in its calibration certificate to be around $0.012 \mathrm{~dB}$. The wavelength contribution to the uncertainty is neglected since the OTDR wavelength is measured using an accurate optical spectrum analyzer $( \pm 0.05 \mathrm{~nm})$.

Table (5): Uncertainty budget for $\left(\Delta S_{A}\right)$ using NPL artifact.

\begin{tabular}{|l|l|l|l|l|l|l|}
\hline $\begin{array}{c}\text { Source of } \\
\text { uncertainty }\end{array}$ & $\begin{array}{c}\text { Value } \\
( \pm)\end{array}$ & $\begin{array}{c}\text { Probability } \\
\text { Distribution }\end{array}$ & Divisor & $\begin{array}{c}\text { Uncertainty } \\
( \pm)\end{array}$ & $\begin{array}{c}\text { Sensitivity } \\
\text { Coefficient }\end{array}$ & $\begin{array}{c}\text { Standard } \\
\text { uncertainty }\end{array}$ \\
\hline $\begin{array}{l}\text { Standard } \\
\text { reference fiber }\end{array}$ & $0.012 \mathrm{~dB}$ & Normal & 1 & $0.012 \mathrm{~dB}$ & 1 & $\pm 0.012 \mathrm{~dB} / \mathrm{dB}$ \\
\hline $\begin{array}{l}\text { Statistical } \\
\text { contribution }\end{array}$ & $0.01 \mathrm{~dB} / \mathrm{dB}$ & Normal & 1 & $0.01 \mathrm{~dB} / \mathrm{dB}$ & 1 & $\pm 0.01 \mathrm{~dB} / \mathrm{dB}$ \\
\hline \multicolumn{2}{|l|}{ Combined uncertainty } & & $\pm 0.016 \mathrm{~dB} / \mathrm{dB}$ \\
\hline \multicolumn{2}{|l|}{ Expanded uncertainty $(\mathrm{k} \approx 2)$} & $\pm 0.032 \mathrm{~dB} / \mathrm{dB}$ \\
\hline
\end{tabular}

The combined uncertainty in $\Delta S_{A}$ is obtained by summing in quadrature the uncertainty contributions stated in Table 5. The expanded uncertainty in $\Delta S_{A}$ of $\left(u_{95}\left(\Delta S_{A}\right)= \pm 0.032 \mathrm{~dB} / \mathrm{dB}\right)$ is obtained by assuming infinite degrees of freedom (DOF) and hence the coverage factor is assumed to be $\mathrm{k} \approx 2$. 
Table (6): Uncertainty budget for $\left(\Delta S_{A}\right)$ using NIS artifact.

\begin{tabular}{|l|l|l|l|l|l|l|}
\hline $\begin{array}{c}\text { Source of } \\
\text { uncertainty }\end{array}$ & \multicolumn{1}{|c|}{$\begin{array}{c}\text { Value } \\
( \pm)\end{array}$} & $\begin{array}{c}\text { Probability } \\
\text { Distribution }\end{array}$ & Divisor & $\begin{array}{c}\text { Uncertainty } \\
( \pm)\end{array}$ & $\begin{array}{c}\text { Sensitivity } \\
\text { Coefficient }\end{array}$ & $\begin{array}{c}\text { Standard } \\
\text { uncertainty }\end{array}$ \\
\hline $\begin{array}{l}\text { Standard } \\
\text { reference fiber }\end{array}$ & $0.021 \mathrm{~dB}$ & Normal & 1 & $0.021 \mathrm{~dB}$ & 1 & $\pm 0.021 \mathrm{~dB} / \mathrm{dB}$ \\
\hline $\begin{array}{l}\text { Statistical } \\
\text { contribution }\end{array}$ & $0.008 \mathrm{~dB} / \mathrm{dB}$ & Normal & 1 & $0.008 \mathrm{~dB} / \mathrm{dB}$ & 1 & $\pm 0.008 \mathrm{~dB} / \mathrm{dB}$ \\
\hline Combined uncertainty & $\pm 0.022 \mathrm{~dB} / \mathrm{dB}$ \\
\hline \multicolumn{2}{|l|}{ Expanded uncertainty $(\mathrm{k} \approx 2)$} & $\pm 0.044 \mathrm{~dB} / \mathrm{dB}$ \\
\hline
\end{tabular}

The combined uncertainty in $\Delta S_{A}$ is obtained by summing in quadrature the uncertainty contributions in Table (6). The expanded uncertainty in $\Delta S_{A}$ of $\left(u_{95}\left(\Delta S_{A}\right)= \pm 0.044 \mathrm{~dB} / \mathrm{dB}\right)$ is obtained by assuming infinite degrees of freedom (DOF) and hence the coverage factor is assumed to be $\mathrm{k} \approx 2$.

A comparison between the calibration results of the OTDR using NPL and NIS artifacts at $1550 \mathrm{~nm}$ and $1310 \mathrm{~nm}$ is given at Figures 8, 9. The comparison shows that both results are comparable and lie within the uncertainty range of each other.

Table 7 summarizes the attenuation scale deviation measurements $\left(\Delta S_{A}\right)$ using both artefacts at $1310 \mathrm{~nm}$ and $1550 \mathrm{~nm}$ :

Table (7): Calibration results of $\Delta S_{A}$ using NPL and NIS artefacts.

\begin{tabular}{|l|l|l|l|}
\hline Calibrator & Wavelength & $\Delta \boldsymbol{S}_{\boldsymbol{A}}(\mathrm{dB} / \mathrm{dB})$ & $\begin{array}{l}\text { Expanded } \\
\text { uncertainty } \\
(\mathbf{d B} / \mathbf{d B})\end{array}$ \\
\hline \multirow{2}{*}{ NPL artifact } & $1550 \mathrm{~nm}$ & -0.033 & \pm 0.032 \\
\cline { 2 - 4 } & $1310 \mathrm{~nm}$ & -0.030 & \pm 0.032 \\
\hline \multirow{2}{*}{ NIS artifact } & $1510 \mathrm{~nm}$ & -0.031 & \pm 0.044 \\
\cline { 2 - 4 } & $1310 \mathrm{~nm}$ & -0.056 & \pm 0.044 \\
\hline
\end{tabular}




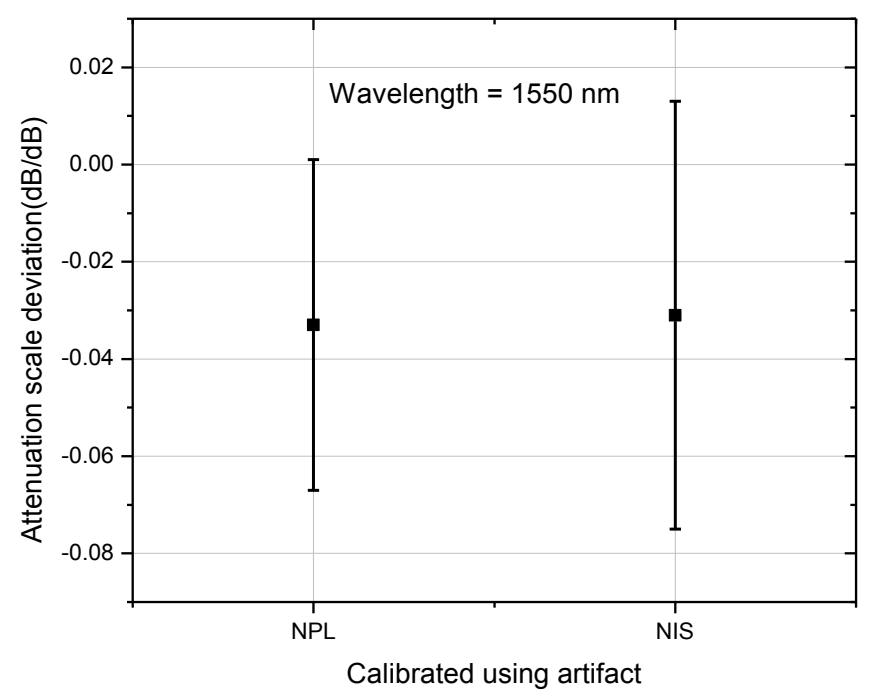

Fig. (8): OTDR attenuation scale deviation calibration at $1550 \mathrm{~nm}$.

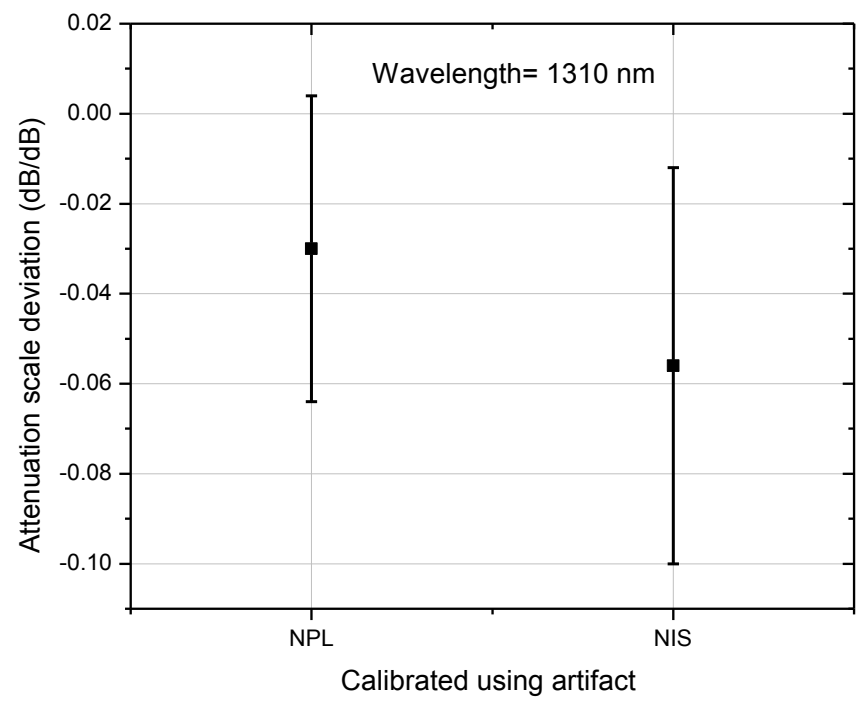

Fig. (9): OTDR attenuation scale deviation calibration at $1310 \mathrm{~nm}$.

\section{Discussion}

It is clear from section 2 and 3 that the standard fiber method has less uncertainty than the external modulation method. This could be attributed to the polarization dependent response (PDR) of the OTDR photodetector. This effect is minimized in the standard fiber method since the measurement is performed between two points at the same fiber (relative measurement). A simple setup is constructed to measure the PDR of the OTDR detector using a paddle 
polarization controller and a power-stable laser source. A trace is acquired while changing the polarization until maximum trace level is obtained and then is changed again until minimum trace level is obtained. The difference between both levels gives an indication of the OTDR detector's PDR. For the OTDR used in this work, the power change due PDR is found to be $0.06 \mathrm{~dB}$, while the power difference change due PDR was found $0.004 \mathrm{~dB}$ for two relative points on the same fiber trace. In order to cancel the polarization effect on the measurements, the polarization paddle is rotated continuously mimicking the function of a scrambler.

\section{Conclusion}

In this paper, two different methods are used to calibrate the attenuation scale of an OTDR, the External Modulation method (EM) and the Standard Reference Fiber method (SRF). Both methods offer advantages and disadvantages. While the EM method can be automated and provides direct traceability to the SI unit of power, the watt, through a calibrated power meter, it has more complex setup and is less accurate than the standard fiber method. In order to provide traceability to the SRF method, the "destructive" cut-back technique is used to measure the attenuation of the SRF. The measurement results are compared to that of the NPL through a previously calibrated fiber artifact. The OTDR calibration uncertainty of the EM method $U\left(\Delta S_{A-E M}\right)$ is found to be around $\pm 0.1 \mathrm{~dB} / \mathrm{dB}$, while the calibration uncertainty of the SRF method $U\left(\Delta S_{A-S R F}\right)$ is found be around $\pm 0.04 \mathrm{~dB} / \mathrm{dB}$ for the wavelengths 1310 $\mathrm{nm}$ and $1550 \mathrm{~nm}$.

\section{Acknowledgment}

The authors would like to thank the Science and Technology Development Fund (STDF) for supporting and funding this research under the umbrella of center of excellence projects-laboratory accreditation.

\section{References}

1. B. Danielson, "Optical time-domain reflectometer specifications and performance testing," Appl. Opt. 24, 2313 (1985).

2. O. Terra "Distance scale calibration of optical time domain reflectometer using active intensity modulation", MAPAN, 6 (2014).

3. European standard, "Calibration of optical time-domain reflectometers (OTDR)”, EN 61746 (2005). 
4. W. Rutzen, W. Stöcklein, C. Unger, "Calibration of optical time domain reflectometers", Optics Communications, 127, 343 (1996).

5. Calibration of Optical Time-Domain Reflectometers (OTDR's), TIA/EIA455-266, Telecommunications Industry Association, Arlington, VA, May (2002).

6. IEEE Standard on Transitions, Pulses, and Related Waveforms, IEEE Standard 181 (2003), The Institute of Electrical and Electronic Engineers, Piscataway, NJ, USA, July (2003).

7. O.Celikel, M. Kücükoglu, M. Durak, F.Samadov, "Determination of attenuation coefficients of single mode optical fiberstandards to be used in OTDR calibrations", Optics \& Laser Technology 37, 420 (2005).

8. BIPM, IEC, ISO. "Guide to the Expression of Uncertainty in Measurement". ISBN 92-67-10188-9 (1995). 